\title{
Review of contemporary architecture projects based on nature geometries
}

\section{Revisión de proyectos de arquitectura contemporánea basados en geometrías de la naturaleza}

\author{
Ma Dolores Álvarez Elipe (Main and Corresponding Author) \\ Universidad Politécnica de Madrid, ETSAM, Departamento de Construcción y Tecnología Arquitectónicas \\ C/. Luxemburgo, 3, P-D, 2으, 45003, Toledo (Spain) \\ mdolores_500@hotmail.com
}

\section{Jesús Anaya Díaz}

Universidad Politécnica de Madrid, ETSAM, Departamento de Construcción y Tecnología Arquitectónicas Avda. Juan de Herrera, 4, 28040 Madrid (Spain)

jesus.anaya@upm.es

\author{
Manuscript Code: 890 \\ Date of Acceptance/Reception: 25.07.2018/03.03.2017 \\ DOI: 10.7764/RDLC.17.2.215
}

\begin{abstract}
Current architecture is characterized by specifying new typologies but not experienced until now in the engineering and architecture disciplines. Architectural free forms with non-euclidean geometries are being developed, which answer to logical analysis and parametric design, and which are tending to the mimesis of behaviour with the nature. Innovative research is developing advanced constructions of complex geometries and free forms by architects like Yushang Zhang, Rajiv Sewtahal, Riemer Postma and Qianqian Cai, Kahn, grupo Matsys, Acadia, AKT, Adler, Karan y Taylor, Emmanuel Ruffo... This paper addresses the analytical study of the set of technical solutions to the design of architectures based on geometric nature structures that will be applied to the building construction. Manufacturing and editing conditions of complex forms will characterize the innovative production systems of contemporary architecture. This study provides a strong documental foundation for research on the significance of new structural and constructive systems in the production of the current architecture.
\end{abstract}

Key words: Current, free forms, complex geometries, nature, innovative structural systems.

Resumen

La arquitectura actual se caracteriza por estar concretando nuevas tipologías no experimentadas hasta este momento en el ámbito de la ingeniería y la arquitectura, desarrollando formas libres arquitectónicas con geometrías no euclidianas, lógicas del análisis y diseño paramétrico y tendentes a la mímesis de comportamientos con la naturaleza. Innovadoras investigaciones están desarrollando avanzadas construcciones de geometrías complejas y formas libres en manos de arquitectos como Yushang Zhang, Rajiv Sewtahal, Riemer Postma and Qianqian Cai, Kahn, grupo Matsys, Acadia, AKT, Adler, Karan y Taylor, Emmanuel Ruffo... Este artículo aborda el estudio analítico del conjunto de las soluciones técnicas de diseño de arquitecturas basadas en estructuras geométricas de la naturaleza que se aplicarán en la construcción de edificios, generando formas complejas cuyas condiciones de manufacturación y edición caracterizarán los sistemas innovadores de producción de la arquitectura contemporánea. Este estudio constituye, por tanto, un fundamento de la base documental para la investigación sobre la significación de los nuevos sistemas estructurales y constructivos en la producción de la arquitectura en la actualidad.

Palabras clave: Actualidad, formas libres, geometrías complejas, naturaleza, sistemas estructurales innovadores

\section{Introduction}

The introduction of geometric studies based on nature and his transfer to the architectural discipline present the possibility of free architectural forms. Parametric virtual prototypes based on nature are created in an economical and accessible way by the use of non-euclidean geometries (Fraile, 2014a). These geometries are designed by the computational prototyping with a multitude of variables like exterior conditions or material design.

The use of these techniques in the aerospace, naval and automotive industry opens doors to expansion in the architectural discipline. The use of parametric design has revealed to be an innovative and enriching experience of architectural project. It is generated new and novel structures of a lot of spatial rich, in which through a series of generative algorithms, the forms "grow" and interrelate in complex topological patterns, according to parameters adjusted by the designer (Fraile, 2014b). To guide this theory is the notion that "parametricism" (a style of curving crystalline biomorphic or angular shapes generated by computer with parametric software) is the inevitable long-term stylistic successor of modern architecture (Buchanan, 2011). 
First of all, we will consider Robert Le Ricolais (1894-1977) ideas. R. Le Ricolais questioned the notion of form as something static. He understands the form like a fluid and in movement concept. Ricolais (Mimram, 1983) tries to discover the relationship between structures extracted from nature (where it finds principally complex models of organization), and the structure of the forms constructed by the humans (this supports that change of scale hypothesis is feasible). In his new structural concepts appear the idea that it is more important to provide the empty in the structure that providing the masses. The structural art consist of how and where to collocate the holes. It is an idea tremendously linked with every form built, because it implies building with holes, building with hollow material and building with hollow and resistant, but weightless structures. The future of architecture is the lightness.

Because we are going to develop a structure from another that we know on nanotechnical scale, we will also consider the reflections of D'Arcy Thompson in his book "On growth and form" (Thompson, 2003). He explains us that we cannot grow the same form in one scale than another. It is because biology form can reflect the physical and mathematical principles. However, we can't have an arbitrary form in all spatial scales, because there are some restrictions imposed by physical laws. For example, it is feasible to imagine an ant with the elephant size, but physical laws make not possible its real existence, because the enormous ant would collapse under its own weight. Therefore, the interaction between geometry and physics restricts the variety of organism forms: this is one of the principal topics we are going to work with; we want to find a mathematic algorism to control the geometries that are already controlled in the nanoscale, to be feasible their conversion to the big scale. That is, our goal is to find the geometric invariants whose structural behaviour remains uniform while the scale is changing, in which geometry, structure and form are the same.

In addition to a variety of possible sizes we have to add the multiplicity of morphologies, which give us a lot of possibilities to work and apply on architecture, generating dynamic architectures with a variable form and a lot of news possibilities. The formation of ordered structures which we are going to work is the result of collective processes of repetition of the unity. In these systems we have scales from the size of a single unit to the scale that characterizes the entire group; in these cases the individual behaviour indicates nothing - or very little - of what happens to the collectivity. These ordered structures, generically, are called patterns.

This way, we are going to study the behaviour of some of these patterns when we change their scale for a bigger one to take part in architecture. The study of this exceptional behaviour in a very big scale like architecture, implies a revolution in a construction world, because the structural concept and its behaviour changes roundly (very new forms that also improve with the loads are going to be produced). This, open some new research, experimentation and innovation paths, with which we can solve current problems.

The research is based on mathematical and geometric basic rules, in which the problems of form are in the first topic mathematic and geometric problems, and the problems of growth are, in fact, physic problems, because the matter reflects physic laws. Therefore, the emergence of ordered structures is a result of physicochemical processes, and like some of the laws that govern these processes are expressed in mathematical terms, then, in the final analysis, the underlying mechanisms which explain the appearance of structures are grounded in maths.

Methodology

The methodology consists of studying experimental architectures which focus on innovation paths using various types of publications. Structures present in the nature or different than usual structures with innovative properties and geometries will be studied. The base of those geometric shapes and the patterns of repetition developed in these architectures and their relationship with nature will be investigated.

The analysis of the architectures presented is done with the objective of finding out if there is a common geometric basis from which all of them start, as well as the determination of whether this base is present in nature. In addition, the objective is to know if the repetitions of patterns contribute to a greater lightness, as it happens in nature.

The final objective is to know if the transition from nature to architecture is totally feasible, and if the structures fulfill the same characteristics that we find in our natural environment. 
In this section experimental architectures are presented and follow novel ways from structures found in nature or with innovative structural properties and geometries, different to ordinary. Architecture is the scale in which structure is the same than form. It can be applied to buildings like skyscrapers, in which the systems are not of flexion or shear. In order to approach the topic we will search examples of relevant architectures in this line.

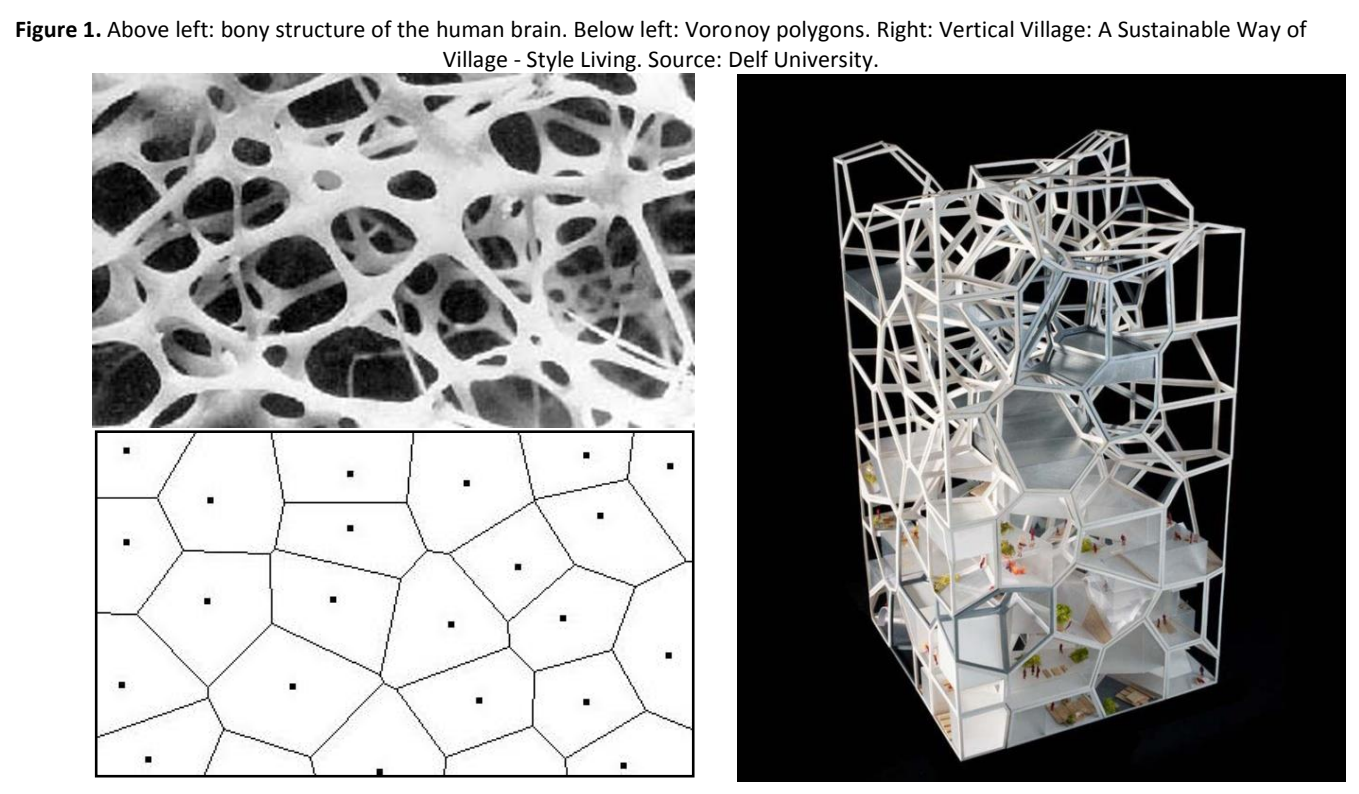

It is discovered that the bony structure of the brain answer to Voronoy polygons. This structure is absolutely stable and a relationship of equilibrium exists in all instant in it. That is, if something is moved all tensions are redirected in order to return to balance: this can be produced because exist a structural continuity. This structure has been applied to architecture in the "Vertical Village: A Sustainable Way of Village-Style Living" project, of Yushang Zhang, Rajiv Sewtahal, Riemer Postma and Qianqian Cai (Charles, 2012). The project is capable of distributing tensions in the space with the same stable structure, because it has been geometrized from the presents in nature polygons of Voronoy.

The City Tower, design by Louis Kahn with Anne Tyng in Philadelphia (1952-1957) will also be object of study. This tower was never built. It is a geodesic skyscraper stabilized by a deployable growth of prestressed concrete tetrahedrons.

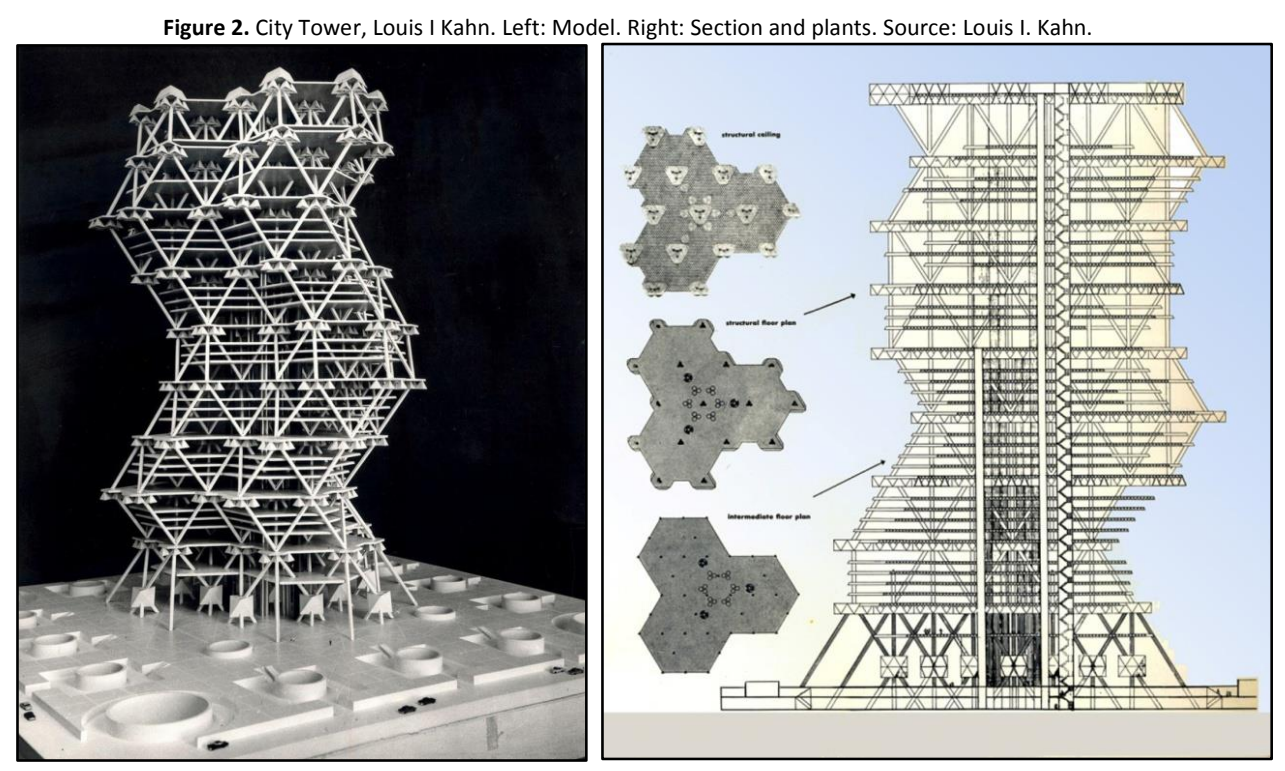

Certain architectures of Saarinen, Utzon, Frei Otto, raised and undeveloped geometries like the Convention Hall of Mies Van der Rohe, fractal developments like AKT, Adler, Karan y Taylor design, developments from the nature elements like 
"Parque de la relajación" in Torrevieja of Toyo Ito, architectures of Matsys group, ACADIA group, Lisa Iwamoto, Emmanuel Ruffo... can be cited too.

Matsys group (Matsys, 2017) studies reflect solutions of geometric layouts in relation with our studies. Diploid lamp series explores some of them inspired in nature patterns, such as scales, panels and barnacles. By the use of parametric models, scripting and digital fabrication, the geometry of light is created, refined and produced.

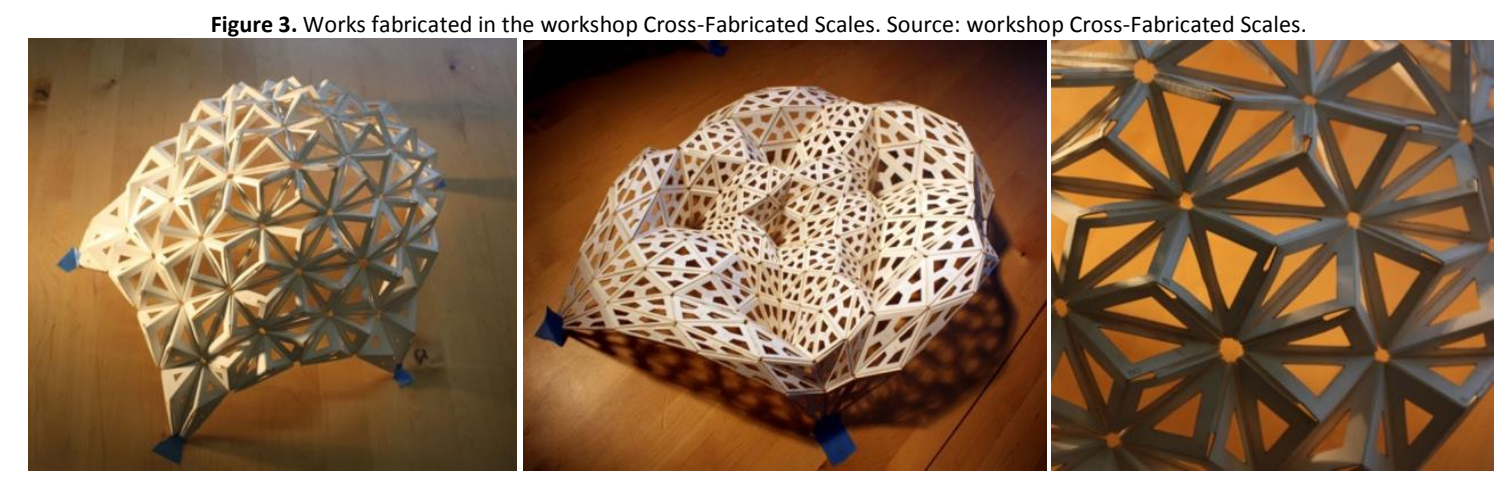

Figure 4. Diploid lamp. Source: Matsys group.
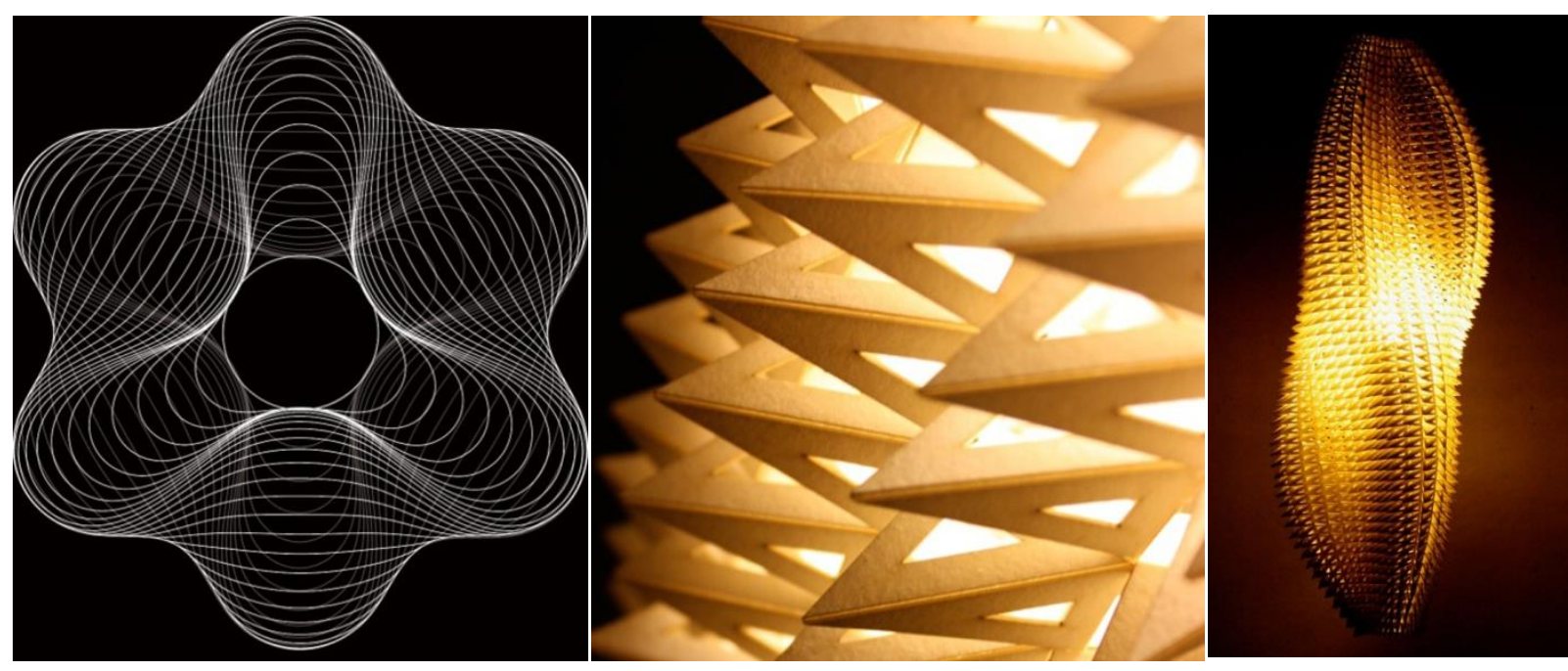

Figure 5. Honeycomb Morphologies. Source: Matsys group.

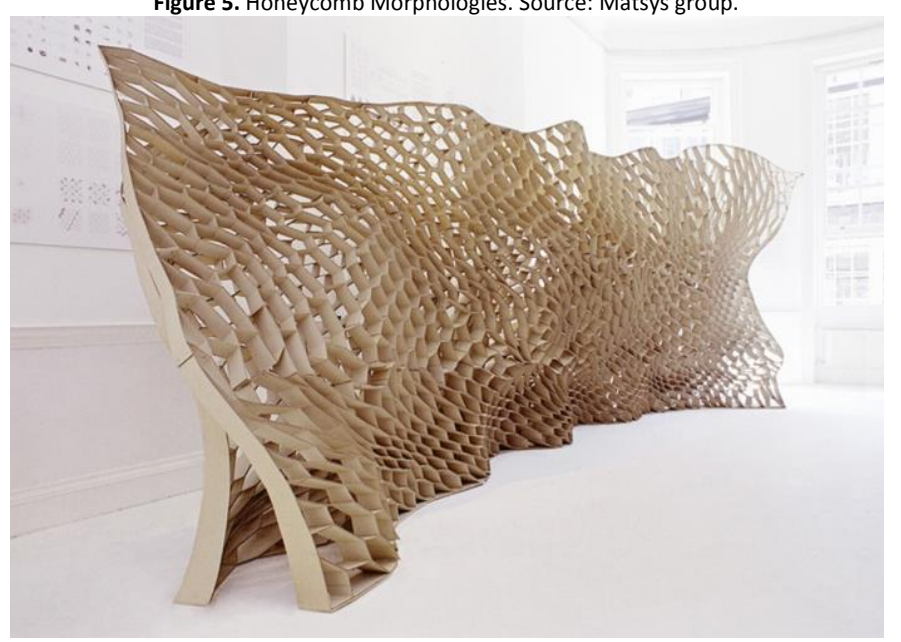

This group also studies honeycomb morphologies, with the central objective of developing a material system with a high degree of integration between design and performance. This integration is inherent to the natural material systems for which they have been developed through evolutionary means that intimately unite the form, the growth and the behaviour of the organism. 
C_WALL project of Matsys group (Matsys, 2017) is also a development in this way: it is the last development in a course zone of investigation about the cellular aggregate structures of honeycomb that have been examined and the Voronoi geometries and their capacity of producing interesting structural, thermal and visual actuations.

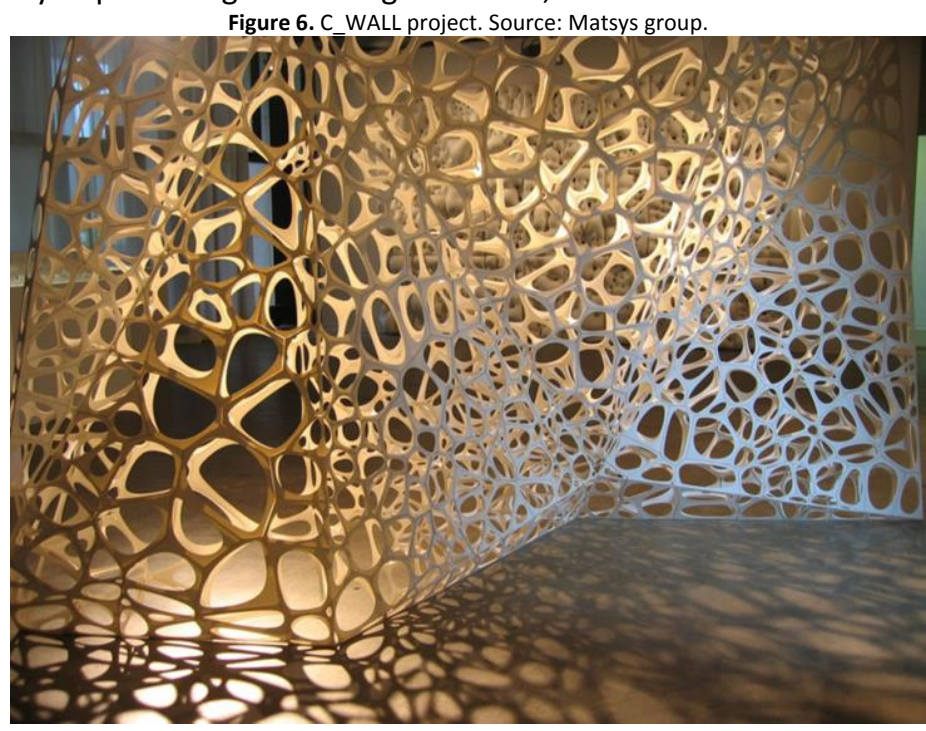

ACADIA group should not be left unmentioned. One of these members is Dave Pigram (Dave Pigram, 2017). The next exposes a development which creates from nature behaviours. This project is an experiment in the affects created by morphogenetic algorithms. These algorithms are designed to generate ornamental distortions within geometry through the internal logic of cellular automation. A technique where an element in space continually changes its state based on the states of those around it, giving rise to emergent patterns.

The project is driven by a series of scripts which build a hex-grid cellular automata and a network of springs which drive the distortion of the more geometrically complex screen. The springs are responding to the changing CA states and enable a non-hierarchical distortion of the network through the use of a non-linear physics solver. Accordingly the influence of an individual CA cell trickles through its neighbors influencing the geometry beyond its immediate adjacencies. The cellular automata operates in a $2 \mathrm{~d}$ matrix and thus the patterns which emerge are most evident across time. Consequently the screen is driven by 3 consecutive generations of the CA to register this change within the final geometry.

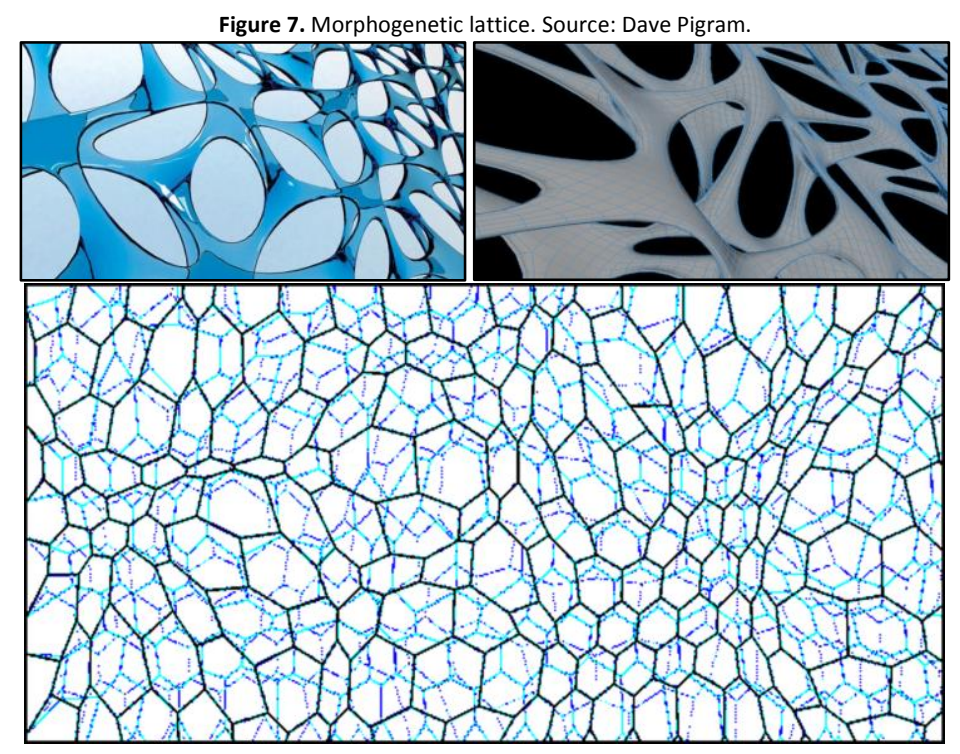

Another example of architecture which is developed from growths that are found in nature are the fractals. The fractals do not maintain the same properties at all scales. In AKT, Adler, Karan y Taylor (AKT, 2008) performances we find some structures developed to the "Fibrous Concrete Istambul Workshop" which have this fractal behaviour. 
Workshops revealed that the interaction between concrete tubes were the key to fabricate some useful structures with its idea. When tubes are joined at maximum effort points, they can be separated in tendons of very narrow diameter. It is an effect against intuition in concrete. It is clear that something like a composite of plastic and concrete could work.

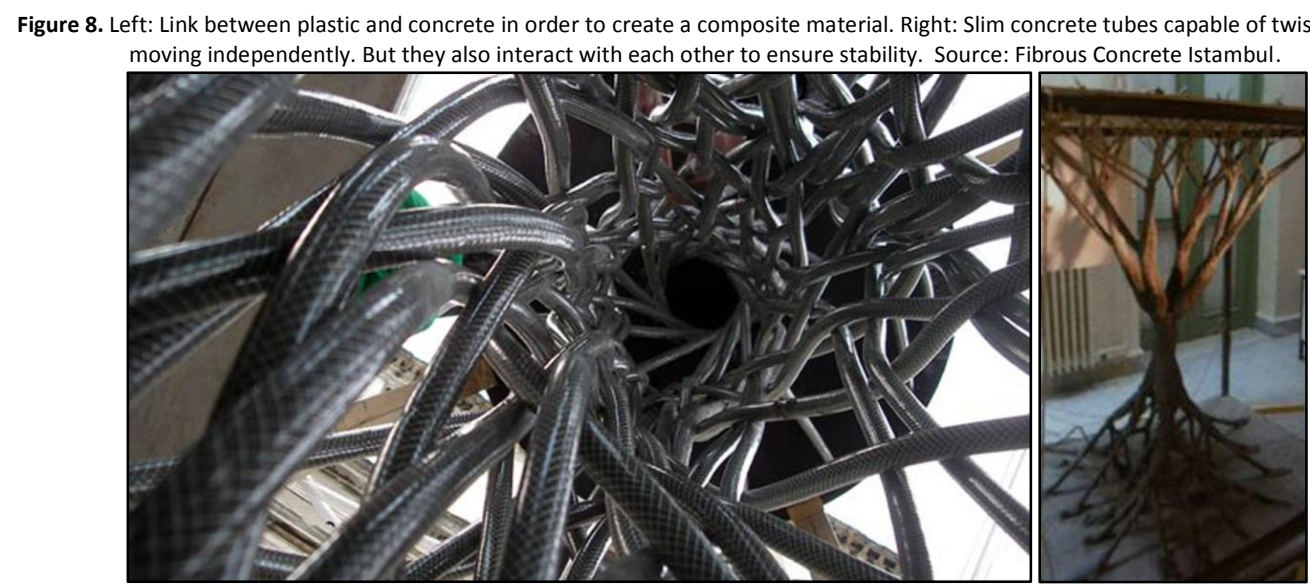

The relation that we want to establish with architecture is also focussed on architectures that develop frame solutions and innovative spatial solutions. AKT, Adler, Karan y Taylor (AKT, 2008) are studying solutions in this way, like the Hexagonal Panelization Strand Link Bridge, in which Future Systems architects were looking for connecting two buildings by a very free surface. They generated the structure with a series of hexagonal and triangular elements. They worked with computational design in order to calibrate the different sizes of these simple forms to obtain a complex form. Finally, they obtained the optimum modulus.

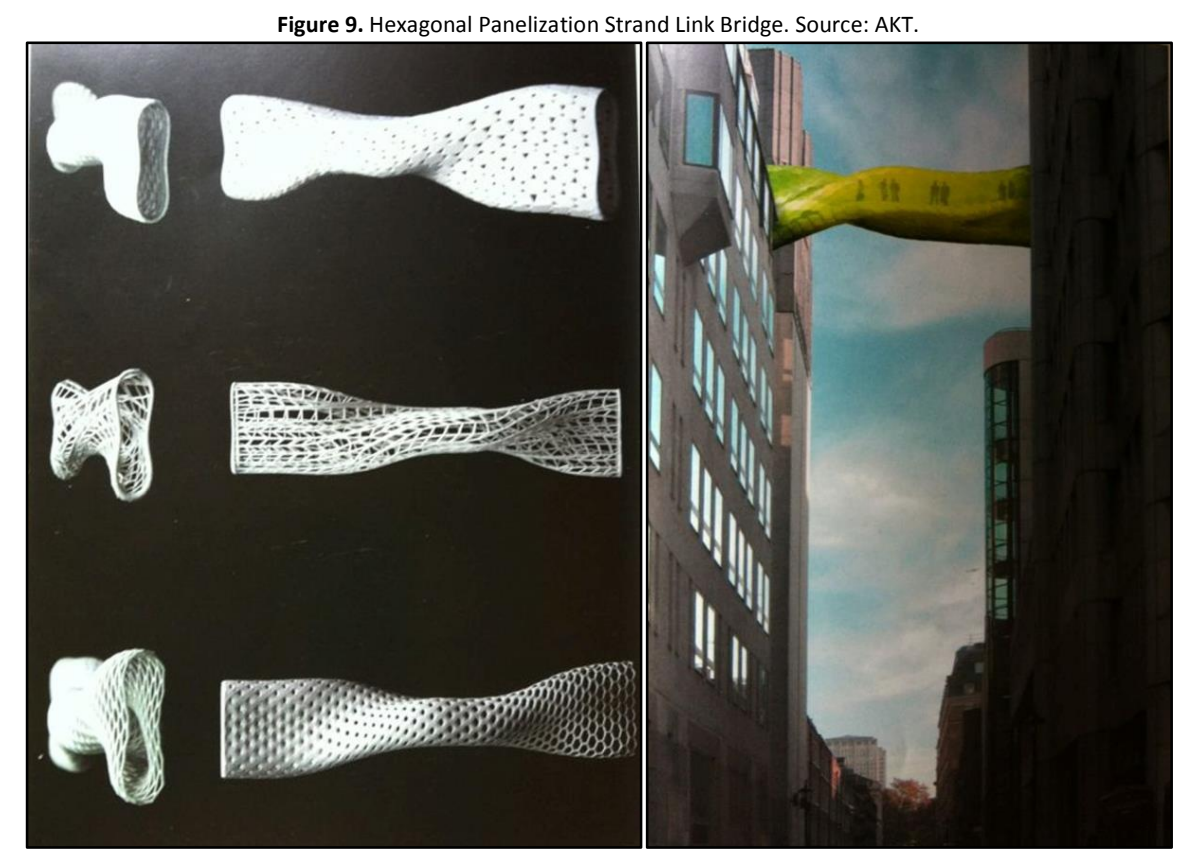

Emmanuel Ruffo (Emmanuel Ruffo, 2012) is also cited by his geometric studies in relation with architecture.

Figure 10. Design of architectural geometries by computational design. Source: Emmanuel Ruffo. 


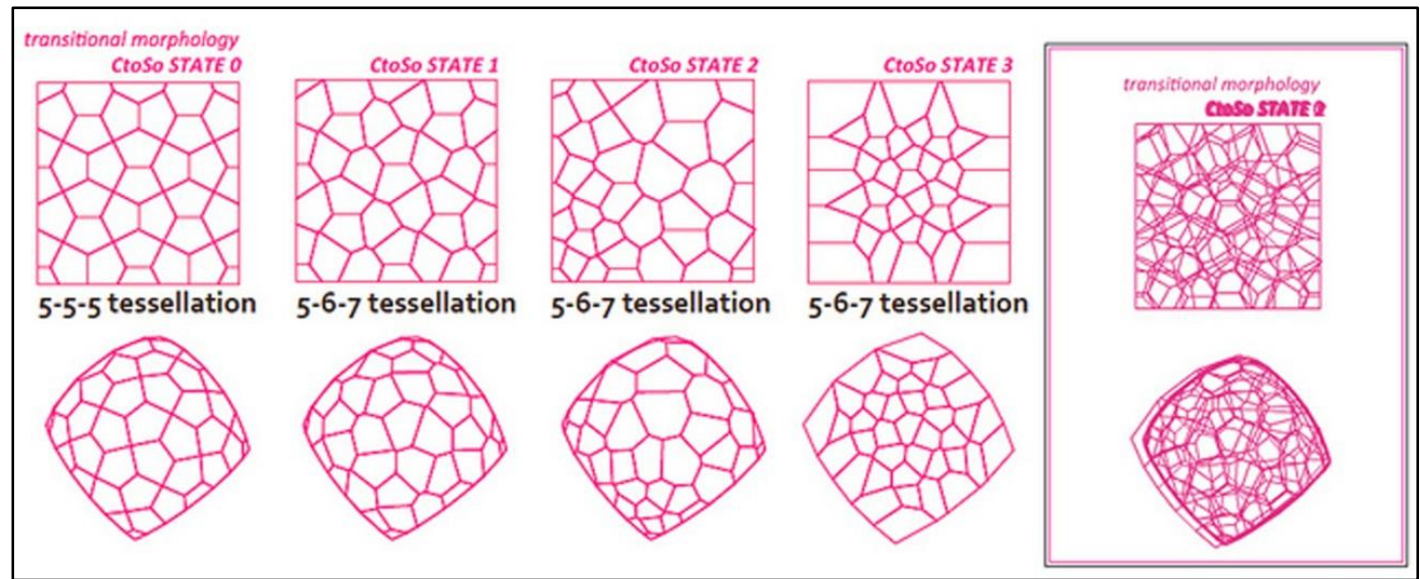

Results, Discussion and Conclusions

By the analysis of submitted architectures is observed that all of them have their origin in a geometric triangular pattern. This pattern is presented continuously in nature and, geometrically speaking, is totally stable.

In the developments studied are presented the fractality or the repetition of structures applying certain turns, compressions... too. We obtain with these structures more or less lightness like in nature.

From all this we deduce that this accommodation from nature to architecture is totally viable. New structures verify the same characteristics that we find in nature. Triangulation is always presented like something totally basic.

References

AKT (2008). Design engineering: AKT, Adams, Kara, Taylor. Kara, Hanif \& Kara Taylor, Adams (ed. lit.). Barcelona: Actar, 319.

Buchanan, P. (2011). In the Autopoiesis of Architecture, Patrick Schumacher introduces a new unifying Thoeory of Architecture. Peter Buchanan Decodes, Dissects an Wighs up Schumacher's arguments. Archit. Rev., 68-76.

Charles. (2012). Energy-[R]evolution. Date accessed 25/02/2017. Available online at: http://www.e-rev.org/post/21508424864/vertical-village-tudelft

Dave Pigram. Supermanoeuvre. Date accessed 26/02/2017. Available online at: http://supermanoeuvre.com/

Emmanuel Ruffo (2012). Emmanuel Ruffo. Date accessed 06/07/2012. Available online at: http://emmanuelruffo.squarespace.com/

Fraile, M. (2014a). Morfogénesis digital. La creación de un paradigma sostenible. XXV Jornadas de Investigación y VII Encuentro Regional: Proyecto y Ambiente SI+AMB, Facultad de Arquitectura, Diseño y Urbanismo, Universidad de Buenos Aires, Bs. As., 2011. Date accessed 26/07/2018. Available online at: https://mfraile.files.wordpress.com/2012/03/morfogenesis-digital.pdf

Fraile, M. (2014b). Morfogénesis digital. Del diseño en serie al parametrismo eficiente. Proceedings of Proyecto UBACyT (056) 2011-2014. Teoría de la Arquitectura en laContemporaneidad. Proyecto y creación científica en las memorias descriptivas. Ciudad Autónoma de Buenos Aires. Argentina. Date accessed 26/07/2018. Available online http://www.academia.edu/2714942/Morfog\%C3\%A9nesis_Digital._Del_Dise\%C3\%B1o_en_Serie_al_Parametrismo_Eficiente

Matsys group (2017) Matsys. Date accessed 26/02/2017. Available online at: http://matsysdesign.com/

Mimram, M. (1983). Structures et formes: étude appliquée à l'ouvre de Robert Le Ricolais. Paris: Dunod.

Thompson, D. A. (1980). Sobre el crecimiento y la forma. H. Blume Ediciones. Spain. 